\title{
Discutindo a (in)equivalência: um exercício de análise
}

\section{Discussing the (in)equivalence: an exercise of analysis}

\section{Glaucia da Silva Henge*}

Resumo: Partindo de uma discussão contemporânea acerca da noção de equivalência em tradução, buscamos discutir $n$ este artigo as definiç ões do que é traduçã o, o estabelecimento de equivalentes entre difere ntes textos a traduzir e a existência de zonas de inequivalência entre eles. Para tanto, propomos um primeiro momento de revisão teórica (baseada nos autores PYM 2011, HURTADO ALBIR 2001 e R ABADÁN 1991), para em seguida discutirmos a produtividade da noção no fazer tradutório através da análise de um trecho de obra literária. Estabelecemos, portanto, uma prática de análise de (in)equivalências e discutimos as possibilidades de escolha do tradutor.

Palavras-chave: tradução; inequivalência; texto literário

Abstract: From a contemporary discussion of the concept of equivalence in translation, in this article we discuss the definition $s$ of translation, establishing equivalents between different texts to be translated and the existence of zones of inequivalence between them. So - firstly we propose a theoretical review (based on the authors PYM 2011, HURTADO ALBIR 2001 and RABADÁN 1991) - to then discuss the productivity of the notion by an analysis of a piece of literary work. Therefore, we establish a practice of analysis of (in)equivalences and discuss the choice of the translator.

Keywords: translation; inequivalence; literary text.

* Docente Instituto Federal de Educação, Ciên cia e Tecnologia; Doutoranda junto ao PP G Letras/UFRGS. Email: ghenge@gmail.com 


\section{Apresentação}

Diferentes definições de tradução acompanham o percurso do tr abalho tradutório. Muitas vezes distintas entre si, mistas ou ainda sobrepostas, as definições marcam também o pr óprio percurso de reflexão sobre a tradução. Inúmeros trabalhos ocupam -se em retomar esse movimento histórico de delineamento da noção de tradução, e o fazem de forma tão adequada que procurarei aqui não fazê-lo novamente, mas sim, partir de um es tado "contemporâneo" da definição do que é atradução. E para tanto, contarei com uma perspectiva funcionalista sobre o fazer tradutório.

Metodologicamente, este artigo está constituído por uma primeira parte de revisão teórica (acerca das noçõ es de tradução, texto literário e inequivalência) e por uma segunda parte de análise práti ca (um br eve comparativo entre tr aduções). Nesta segunda parte, discuto dois trec hos significativos de uma obra literária tradużda para o português brasileiro (a qual me dedico em outro s estudos teóricos ), com o objetivo de verificar as (in)equivalências e soluções interessantemente encontradas pelos tradutores e materializadas em seus textos finais.

\section{Definição de tradução}

Por tratar-se de uma discussão milenar, a questão da tradução pode ser abordada sob di ferentes ângulos e sob diferentes perspectivas. Contemporaneamente, podemos retomar a definição de Hurtado Albir (2001: 25) acerca do que é traduzir, quando a autora distingue a tradução como uma habilidade, um saber fazer $\mathrm{n}$ o qual se recorre ao processo tradutor e se resolvem problemas de tradução caso a caso. Pym (2011: 14) toma a tradução em um sentido amplo, no qual se estabelece um conjunto de processos que vão de um texto de origem a partir do qual se traduz para um texto de destino em 
Henge, G. da S. - Discutindo a (in)equivalência: um exercício de análise

que a tradução é produzi da. O papel do tradutor estaria centrado na identificação dos problemas de traduç ão e na seleç ão de uma solução e m detrimento de outras, sendo que tal seleção pode ser aperfeiçoada ou melhor realizada a partir do conheci mento do tradutor sobre distintas teorias da tradução, isto é, a partir da teorização do fazer tradutório.

Neste artigo estudarei um paradigma em específico, o da equivalência e também seu correspondente direto e mutuamente constitutivo, o da inequivalência. Entretanto, para melhor compreendê-lo, devem os precisar o que falamos quando falamos em traduç ão. Para is to, busco o diálogo com a perspectiva funcionalista ac erca da tradução, mas sem retomá-la detalhadamente dadas as limitações e pretensões deste texto.

Para tanto, qualquer reflexão sobre a tradução deve considerar quatr 0 pressupostos básicos (HURTADO ALBIR 2001: 28): a razão de ser da tradução sendo a diferença entre línguas e culturas ; a tradução em s ua finalidade comunicativa; a tradução em sua relação com o destinatário que necessita dela para conhecer a língua e cultura do text o original e a tradução condicionada pela finalidade que persegue em cada caso. Neste sentido, $f$ ica evidente a importância da competência tradutória, is to é, da capacidade de colocar em ação uma relação entre línguas e culturas distintas que até então não exis tia, de acordo com a fina lidade e o destinat ário desta tradução. Há, como se vê, uma via de muitas mãos, isto é, uma sé rie de fatores determina e coexiste no e durante o processo tradutório.

A mera correspondência de elemen tos entre uma l íngua e outra não constitui, por sua vez, a essência da tradução, pois existem princípios básicos que a regulam (H URTADO ALBIR 2001: 31-37), sendo eles: a primazia da comunicação e da adequação à língua de chegada; a atualização do texto (o sentido); a intervenção do contexto; os aspectos culturais e o destinatário da tradução; a finalidade da tradução; e a tradução como processo mental. Estes princípios explicitam os diferen tes graus de aproxi mação ou distanciam ento entre as línguas de chegada e de partida. 0 percurso que se estabelece entre elas é marcado por matizes nos quais conhecim entos intralinguísticos e extralinguísticos se entrecruzam e sobredeterminam, exigi ndo 
instrumentalização e práticas de pes quisa e reflexão sobre o próprio f azer tradutório.

Após retomar algum as definições amplamente discutidas de tr adução (HURTADO ALBIR 2001: 37-40) entr e elas: como atividade entre línguas (V INAY E DARBELNET 1958), como atividade textual (S ELESKOVITCH Y LEDERER 1984; CATFORD 1965; HOUSE 1977), como ato de comunicação (N IDA Y TABER 1969; HATIM Y MASON 1990; Hermans 1991; Toury 1980; SNell Homby 1988; Hewson y MARTIN 1991; ReISS Y VERMEER 1984; LVÓVSKAYA, 1997) e a tradução como uma produção (VázQUES AYORA 1977; Seleskovitch y Lederer 1984; SteineR, 1975; Delisle 1980; Bell 1991) Hurtado Albir (2001: 41) propõe a já canônica definição de tradução como "um processo interpretativo e comunicativo que consiste na reformulação de u $\mathrm{m}$ texto com os meios de outra língua e que se desenvolve em um contexto social e com uma finalidade determinada". Temos aqui, como se pode ver, o delineamento da diversidade que permeia o processo tradutório: a presença do sujeito que traduz, a coexistênci a de línguas (de partida e de chegad a) e os fatores contextuais, sem me nosprezar ou subval orizar nenhum deles. Ainda para Hurtado Albir (2001: 41) toda e qualquer definição de tradução deve incluir obrigatoriamente a caracterização de três aspectos: texto, ato de comunicação e atividade cognitiva de um sujeito.

A convergência dess es aspectos vai ao encontro dos fatores s empre presentes no processo tradutório segundo Aubert (1993: 76), que são: os fatores vinculados ao ato tradutório em si, como a intenção, a competência, a relação com o texto original e como destinatário; os fatores relacionados com o código, a língua e a cultura tanto de pa rtida quando de chegada; e, os fatores que derivam das funções do tex to e do grau de identidade ou diversidades destas funções no contexto do ato de tradução e no texto original. 0 u seja, não é possível desconsiderar, jamais, a c oexistência de uma trama entre texto original/tradutor/ato tradutório, evidentemente considerando as determinações externas destes elementos, entre elas a subjetividade, a historicidade, a funcionalidade e a inte rpretação. Daí poder-se falar em um compromisso de fidelidade com a imagem que o tradutor cria para si mesmo das expectativas, necessidades e possibilidades dos receptores finais (A UBERT 
HENGE, G. da S. - Discutindo a (in)equivalência: um exercício de análise

1993: 75), o que o determina, em diferentes graus, como instrumento humano para o ato tradutório.

Em síntese, ao abor darmos o processo tra dutório, portanto, podemos perceber o movimento entre textos co mo aponta Pym (2011) ; dentro de um conjunto de processos, nos quais a in terpretação e a comunicação se dão em contextos sociais es pecíficos, como define Hurtado Albir (2 001); e cujo compromisso de fidelidade com o tex to original e com o receptor do texto traduzido mantém um jogo entre o di verso (entre línguas e culturas) e o idêntico (a possibilidade de correspondência), como discute Aubert (1993).

\section{A noção de equivalência em tradução}

Ao longo da história, pensar em tradução implicou sempre em r efletir sobre algumas noç ões centrais (transversais e recorrentes), tais com 0 equivalência tradutora, invariável tradutora, unidade de tradução, método e técnicas de tradução, estratégias, problemas de tradução e erros de tradução; que se relacionam diretamente com a análise da tradução, segundo Hurtado Albir (2001: 201) e mais precisamente com a noção-chave de fidelidade. Todas essas noções, segundo a au tora, estão relacionadas com a própria concepção de tradução de que se parte para discutí-las e to das permanecem atuais e produtivas nos estudos de tradução.

Interessa-nos, então, a noção central de equivalência, que está, por sua vez, intrinsecamente ligada à noção de fidelidade. Historicamente, a fidelidade tem sido entendida como a relação que se estabelec e entre o texto original e sua tradução (HURTADo AlBIR 2001: 202). Porém, poderia se entender fidelidade em seu sentido estrito, como unicament e sendo a existência de um vínculo entre um texto original e o texto traduzido, mas sem explicar a natureza deste vínculo (HURTADO AlBIR 2001: 202). Ao dimensionar a fidelidade com 0 simplesmente o vínculo entre o texto ori ginal e sua tradução, Hurtado A lbir 
(2001), entretanto, não o menospreza, mas sim, assinala as três dimensões que caracterizam e condicionam a fidelidade em tradução.

Para a autora (HURTADO ALBIR 2001: 202), as dimensões da fidelidade em tradução são: a subjetividade, e da í o importante e necess ário papel de intervenção do sujeito tradutor; a historicidade, ou seja, o contexto históricosocial em se dá a tradução e s uas repercussões no texto; e a funcionalidade, isto é, as i mplicações da tipologia textual, da língua e do m eio de chegada, bem como a finalidade da tradução. Estas três dimensões, afirma a teórica, influenciam de formas diversas o ser fiel ao texto original, de acordo com cada caso. Ou seja, pode-se ser fiel ao text o e marcar a su bjetividade, o fazer do tradutor, suas escolhas e recusas; pode-se ser fiel e priorizar os impactos sóciohistóricos do texto traduzido ou ainda, ser fiel e apenas prioriz ar a função a que se destina o texto da tra dução, porque e par a quem ele está sendo produzido.

Interessante observar que para Hurt ado Albir (2001: 211) "a busca de equivalências não $c$ onsiste em uma reativação de equi valências préestabelecidas", e sim, "um complexo processo no qual se produz um movimento mental contínuo de as sociações sucessivas de ideias, de deduç ões lógicas, de tomadas de decisão". Talvez este seja um aspecto m uito particular e significativo da noção de equivalência, uma vez que ela não se dá a priori entre dois textos (texto de origem e texto me ta), sendo estabelecida através de um processo subjetivo de colocação em relação a do sujeito tra dutor no ato tradutório, como processo cognitivo, cultural e linguístico.

Pym (2011: 21) afirma que é a equivalência enquanto valor compartilhado entre o texto original e o texto traduzido o que diferencia este último dos demais textos possíveis, portanto, falar de traduçõe s diferentes implicaria em tratar de diferentes tipos de equivalências. 


\section{A noção de inequivalência}

Para pensar a inequivalência, Rabadán (1991: 110) pontua que da mesma forma que não existe a equivalência absoluta, também não se pode considerar a inequivalência total, ou seja, a intrad uzibilidade essencial. Para a autora, a história da tradução mostra que a intraduzibilidade não existe por si, tampouco a inequivalência, mas sim que há limitaçõ es de tipos diferentes no processo tradutório de estabel ecimento de equi valentes. Para melhor abordar es ses tipos, Rabadán (1991) partindo de um estudo anterior (SANTOYO 1987) divide-os em três grandes áreas:

a. As inequivalências derivadas de questões linguísticas

b. As inequivalências impostas por fatores de caráter extralinguísticos

c. As inequivalências de tipo ontológico (lacunas, objetivas e universais ou pessoais do tradutor).

A seguir, retomamos sumariamente cada uma delas.

Os limites impostos pelo caráter linguístico do texto original estão relacionados a diferentes aspectos da língua e de seu uso. Em termos de variação intralinguística, isto é, o quantoa própria língua do texto original pode variar sobre si mesma, a autora destaca três variações marcadamente limitantes da equivalência: as variantes geográficas, as diacrônicas e as sociais. Neste sentido, os diferentes dialetos, estabelecidos como tais entre si pela tomada de um dialeto como norma padrão (geralmente o falado pelas eli tes intelectuais e/ou econômicas) e pela consider ação dos demais com o "característicos" de um falar regional esocial, podem constituir o texto original de dois modos específicos (RABADÁN 1991: 111): ora como totalidade (quando um texto é completamente es crito no dialeto tomado como padrão para o autor), ora como parcialidade (quand o o autor seleciona trechos, para caracterizar um personagem por exemplo, e evidencia a variação em relação à língua padrão). 
Outro limite imposto à tradução é o dos estados anteriores da língua em relação ao atual, poi s os diferentes estados diacrônicos das línguas não são, muitas vezes, equiparáveis (RABADÁN 1991: 112). Alguns tradutor es optam por buscar um equivalente diacrônico na língua a ser traduzida, buscando para tanto, uma equivalência funcional, porém, nunca exata, a través do us o de arcaísmos, por exemplo.

Outra variação que é intrali nguística, mas que possui c onotação extralinguística segundo a autor a, é a ex istência dos registros sociais. Estes registros que determinam usos particul ares da língua dizem respeito aos parâmetros ligados a grupos sociais, ta is como idade, sexo, profissão, nível socioeconômico, etc. segundo Rabadán (1991: 114). Geralmente o uso da língua pelas classes sociais privilegiadas é to mado como regra geral e passa a ser a forma correta de escrita, ainda seg undo a autora. Assim, mais uma vez, a variação que difere da língua padrão é utilizada como caraterização linguística de um personagem ou de um grupo social em trechos ao longo do texto orignal. Sua tradução, portanto, pode não ser possível, quando não se tem os mesmos parâmetros ou grupos na socie dade cuja língua é a da traduçã o, isto é, "as variantes sociais se podem traduzir ( $\mathrm{m}$ ais ou menos) sempre e quando os contextos situacionais e a organização social sejam relativamente equiparáveis em ambos os polissistemas" (RABADÁn 1991: 115).

Além das variações geográficas, diacrônicas e sociais, outros limites linguísticos existem na tradução. Entre ebs, os limites metalinguísticos (quando há uso metalinguístico da linguagem em trechos do texto a tra duzir) exigem que se leve em consideração quem é o leitor, isto é, a audiência potencial (RABADÁN 1991: 116) e qual o seu grau de entendimento/interesse quanto à metalinguagem empregada.

Assim também a função intratextual do signo (a $f$ orma do significante como fundamental para o sentido) impe de muitas vezes a equivalência na tradução, ainda que a função semântica seja mantida, algo permanece na zona de inequivalência linguística (RABADÁN 1991: 118). Estas dificuldades impostas pelo uso motivado dos signos se materializam e podem ser agrupadas segundo a autora em/devido a: polissemia, ambiguidade, jogos de palavras e metáfora, 
sendo que elas não têm o mesmo stat us nem incidem da mesma forma na relação que se dá entre as línguas na tradução (RABADÁN 1991: 119).

Indo além dos recursos linguísticos, outro fator relevante para as zonas de inequivalência real está relacionado aos limites que estabelecem as normas para a tradução. Neste sentido, a h istoricidade da tradução, bem com o os critérios de tempo, lugar e gênero influenciam significativamente $o$ ato tradutório. São os chamados "comportamentos tradutores" que determinam o que se considera aceitável ou não como tradução (RABADÁn 1991: 131).

Uma última área de inequivalência explorada por Rabadán (1991) é a metáfora. Dada a complexidade da noção e de seu impacto na tradução, deternos-emos aqui a uma simples retomada de sua definição enquanto tal, pois a autora propõe uma classificação das metáforas segundo sua recepção, além de uma generalização dos graus de inequivalência potencial conforme a classe da metáfora. Metáfora para Rabadán (1991: 135) é "a aplicação a um objeto ou fenômeno do nome de outro em virtude de uma relação de semelhança entre ambos".

Em seu estudo, Rabadán (1991: 149) ai nda acrescenta outros limites à equivalência, pontuando os suportes extralinguísticos como condicionantes da parte linguística. Isto é, out ros códigos interferem na po ssibilidade de transferência entre polissistemas, pois são parte do t exto como um todo, no caso do cinema, da canção, das tiras de humor, le gendas, entre outros. Esse tipo de material a traduzir seria, portanto, segundo a autora, uma traduç ão subordinada.

Outros limites extralinguísticos à tra dução são proporciona dos pelas representações linguísticas de zonas de experiência não com partilhada, os vazios referenciais (DAGUT 1981 apud RABADÁN 1991: 164) e o humor. No caso dos vazios referenciais, como amplamente oc orre no caso das receitas culinárias, exemplo dado pela autora, não existem correspondentes entre os polissistemas, por não existirem os mesmos referentes, $n$ ão são pos síveis os mesmos signos pela simples ausência de significado, gerando ausência de significante.

Finalmente, o úl timo grande grupo de inequivalências apontado pela estudiosa que aqui $r$ etomamos, resulta dos limites do próprio conhecimento 
humano. Isto porque, sendo o tradutor evidentemente humano, algumas lacunas suas podem interferir no texto meta. Entretanto, "o tradutor não tem direito de roubar do leitor meta o trabalho do autor ori ginal, seja por interpretações deficientes ou por supres sões voluntárias derivadas de sua desinformação" argumenta Rabadán (1991: 169).

Antes de partir para o exercíc io de análise, precisamos brevemente retomar a especificidade do texto que ser á avaliado: o texto li terário, cuja tradução apresenta particularidades a serem consideradas ao longo do processo.

\section{A tradução literária}

Dentro do universo de teorização da tradução literária, lembramos que Bassnett aborda a questão da tradução literária não necessar iamente para avaliar os produtos finais, mas sim, para mostrar os problemas específicos de tradução que podem emergir dos critérios de seleção individuais do tradutor (BASSNETT 2002: 82). Ainda que a poesia seja privilegiada nas discussões acerca da tradução literária, a prosa também é foco de estudo e reflexões.

Neste sentido, ao lembrar que o papel essencial do tradutor é ser leitor, a autora retoma a noção de equivalência na tradução da prosa e pontua que o tradutor deve primeiramente determinar a função do sistema da língua-f onte (SL) e então encontrar um sistema da língua-alvo que adequadamente preste aquela função (BASSNETT 2002: 123). Este aspecto rela tivo à tradução literária em específico é mui to importante, uma vez que os blocos a traduzir (ou unidades de tradução) são determinados pelo tradutor.

Assim, definir a função que determinados elementos do texto de origem exercem entre si é c rucial para garantir a equivalência ou ainda estabelecer inequivalências no texto meta. Tal consideração vai ao encontro da certeza de que a equivalência nunca foi uma questão de valores exatos (PYM 2011: 24). Isto porque cabe ao tradutor perceber que o texto literário é feito de um conjunto 
de sistemas complexos existindo em uma relação dialétic a com outros conjuntos de sistemas que vão muito além das bordas, dos limites pontuais do texto em questão (BASSNETT 2002: 83).

\section{Exercício de análise}

A obra sel ecionada para este exercí cio de análise ac erca da noção de (in)equivalência na tradução literária é o romance “ Great Expectations” do britânico Charles Dickens. Escrito entre 1860 e 1861 no formato de publicação em uma revista semanal do autor e la nçado como livro em julho de 1861, o romance conta a trajetória de vida um órfão criado pela irmã casada com um ferreiro em uma casa humilde e que, ainda jovem, herda uma fortuna e deve tornar-se um cavalheiro. A história se passa no início do século XIX e é contada pelo próprio personagem, num tom autobiográfico que mistura lembranças e arrependimentos.

0 romance, de um $\mathrm{m}$ odo geral, pe rmanece muito atual, pois discute questões morais como ambiç ão, gratidão, indiferença e vingança, al ém de abranger também a relação dos sujeitos na sociedade permeada pelos valores atribuídos ao dinheiro e ao status.

Por tratar-se de uma obra extensa, recortaremos dois trechos breves, porém muito interessantes, do capítulo sétimo do romance. Neste capítul o, o narrador-protagonista lembra um período de sua infância quando, ainda pobre, vivia com a irmã e o cunhado fe rreiro. 0 vínculo de $\mathrm{c}$ arinho entre o narrador (menino) e o adulto é evidente e há uma espécie de cumplicidade entre ambos, pois são maltratados pela irmã/ esposa, extremamente fria e agressiva. $\mathrm{N}$ a passagem selecionada, os dois personagens Pip (o menino) e Joe (o ferreiro) conversam ao lado da lareira na cozinha da casa simples.

Para melhor sistematizar os recortes, chamaremos cena 1 o momento em que Pip e Joe discutem a carta escrita pelo meni no na lous a, e cena 20 momento em que Joe conta sobre sua infância. 
O texto original de Dickens circula no Brasil amplamente nos dias de hoje em duas publicações diferentes e são estas que também nos servem como objeto de análise. Assim, selecionam os as duas cenas supracitadas nas traduções de: Paulo Henriques Britto (publica da pela editora Penguin Companhia das Letras em 2012) e Doris Goettems (publicada pela editora Landmark em 2013).

Em seguida, reproduzimos os três fragmentos de te xto de cada cen a (texto de origem e os dois textos-meta), para depois, discutirmos a existência de (in)equivalências no process o tradutório através de seu produto fin al. Evidentemente, estamos cientes das limitações de uma análise desta natureza, que toma o produto de um processo já acabado, porém, cremos que aos $f$ ins didáticos a que se de stina tal análise, ainda assim será produtivo perceber o funcionamento da noção de equivalência na prática de tradução.

\section{Cena 1}

With an alphabet on the hearth at my feet for reference, I contrived in an hour or two to print and smear this epistle:

'MI DEER JO i OPE U R KR WITE WELL i OPE I SHAL SON B HABELL 42 TEEDGE U JO AN THEN WE SHORL B SO GLODD AN WEN I M PRENGTD 2 U JO WOT LARX AN BLEVE ME INF XN PIP.'

There was no indispensable necessity for my communicating with Joe by letter, inasmuch as he sat beside me and we were alone.

(DICKENS 2013: 562)

\begin{tabular}{|c|c|}
\hline Tradução de Paulo H. Britto & Tradução de Doris Goettems \\
\hline $\begin{array}{l}\text { Com um alfabeto a meus pés para } \\
\text { me servir de referência, em uma ou duas } \\
\text { horas compus, após muito rabiscar e } \\
\text { apagar, esta epístola: }\end{array}$ & $\begin{array}{l}\text { Com um alfabeto aos meus pés, } \\
\text { junto à lareira, para servir de referência, } \\
\text { consegui, depois de uma ou duas h oras, } \\
\text { produzir a seguinte epístola: }\end{array}$ \\
\hline $\begin{array}{l}\text { cAru JO ispEru Q sTejaS bEm } \\
\text { ispEru Q em bREvi eu PoçO enCInArti JO } \\
\text { ai vAi Se MunTo Bom quAnDu eu fOr tEu } \\
\text { apRenDis JO vaMu faZe gRAndis } \\
\text { batUsCaDas SaUdasOns PiP. }\end{array}$ & $\begin{array}{l}\text { "Me U Ca Rro JO esPer q voc eTÁ } \\
\text { bem eU esPer qe log posso en Ciná Td pr } \\
\text { ocÊ JO e e mTão tDO estará mTO bem e } \\
\text { quando Eu soU aprendis pra voc JO eM } \\
\text { bleve SeU sincer Amgo PIP” }\end{array}$ \\
\hline $\begin{array}{l}\text { Não era absolutamente } \\
\text { indispensável que eu me comunicasse } \\
\text { com Joe através de uma carta, já que ele } \\
\text { estava sentado ao meu lado e estávamos } \\
\text { sozinhos. (pp. 71) }\end{array}$ & $\begin{array}{l}\text { Não era indispensável que eu me } \\
\text { comunicasse com Joe através de uma } \\
\text { carta, já que ele estava sentado ao meu } \\
\text { lado e estávamos sozinhos. (pp. 54) }\end{array}$ \\
\hline
\end{tabular}


HENGE, G. da S. - Discutindo a (in)equivalência: um exercício de análise

Primeiramente, podemos per ceber e ressaltar o comportamento tradutório predominante em ambas as traduções reproduzidas aqui. Existe de forma clara em cada texto meta a preo cupação de estabelecer a equivalência com o texto de origem, como pontua Hurtado Albir (2001) através dos aspectos de subjetividade, historicidade e funcio nalidade do texto. Como frisa Aubert (1993) a busca pela fidelidade faz com que, ainda distintos entre si por algumas variações, os textos meta sejam marcadamente esforços de interpretação do tradutor na busca pela permanência da funcionalidade mais acentuada do texto de origem: ser prosa literária e todos os recursos empregados para tanto. E nesta busca pela fidelidade, ambos os tradutores são exitosos.

Em termos pontuais, podemos observar o trabalho dos tradutores quanto à sintaxe e à pontuação empregada no texto origem. Há, sem dúvida alguma, um esforço de mantê-la quase imutáv el, adequando ao míni mo possível o sistema de chegada. Como podemos ver na frase de abertura do parágrafo em análise.

Existe no uso das vírgulas, nos tempos e modos verbais, bem como na ordem sintática nas traduções que são reproduzidas, um movimento de quase apagamento das vari ações sintáticas en tre o ingl ês britânico e o português brasileiro.

De certo modo, podemos verificar que, em ambas as traduções, são priorizados os valores, a função de cada elemento textual no texto de origem para estabelecer a tradução il ocutiva-enunciativa (WOTJAK, s.d.) de fato. Isto é, a expressão de um contexto no qual o enuncia dor, no papel de narrador, busca estabelecer uma descrição que situe o ouvinte/leitor do ambiente em que se passam os eventos seguintes, bem como o estado de ânimo do enunciador. Neste caso, o narrador-pe rsonagem escrevera, após m uitos esforços, uma carta para o outro personagem. Entretanto, por ser ainda criança e estar frequentando a escola, a carta vai apresentar características peculiares a este período ainda de alfabetização, de iniciação à escrita do personagem, e também, do quase total analf abetismo do ou tro personagem que apena $s$ reconhece as iniciais do seu próprio nome. 
O autor do romance escolhe reproduzir a carta do personagem no modo de escrita rudimentar em que teria sido feita, isto é, o efeito de veracidade que o texto apresenta se dá pelo que Rabadán (1991) menciona ser variação intralinguística. Ou seja, nesta passagem, um registro emerge como diferente da norma padrão utilizada ao longo de todo o texto. E estabelece, a nosso ver, uma zona de inequivalência real para a tradução.

Isto porque as marcas da oralidade e dos equívocos de escrita expressos na carta são próprias da língua inglesa, não exis tindo, da mesma forma, na língua portuguesa, pela própria diferença dos signos. Há, como cita Rabadán (1991), uma função intratextual do signo no texto de origem, que marca pouca habilidade com a norma escrita da língua. Como vemos em: 'MI DEER J O i OPE U R KR WITE WELL i OPE I SHAL SON B HABELL 42 TEEDGE U”, trecho que inicia a carta. Sua forma em língua inglesa ( $a$ inda apresentando problemas quanto à norma culta) seria: "My dear J oe, I hope you are quite well, I hope I shall soon be able for to teach you".

Esta zona de inequivalência real é tratada de forma similar pelos tradutores, e parece-nos muito interessante. Ambos, ainda que concretamente diferentes, fazem um movimento em direção ao texto de destino como descreve Pym (2011) e mantêm o aspecto do texto de origem, buscando conservar esse tom de escrita rudimentar (em fase de aquisição do código escrito e cheio de marcas da oralidade) no texto de destino.

Assim, produzem unidades de tradução tais como: “ cAru J O ispEru Q sTejaS bEm ispEru Q em bREvi eu PoçO enCInArti (Britto) ou ainda Me U Ca Rro J O esPer q voc eTÁ bem eU esPer qe log posso enCiná Td pr ocÊ" (Goettems). Os dois tradutores optam por reforçar a troca de vogais finais como "o" por "u", ou ainda o uso errôneo dasfricativas como "s" em suas variações "ç", "ss", além da separação v ocálica e do uso aleatório de maiúsculas . Todos es tes equívocos são comuns pelos aprendizes do código escrito em norma culta do português.

Ainda que a forma dada aos equírocos destoe dos resultados de pesquisas quanto aos equívocos de letram ento que realmente oco rrem em português (dificilmente o aprendiz usaria l etra maiúscula no meio da palavra, mas sim, 
HENGE, G. da S. - Discutindo a (in)equivalência: um exercício de análise

escreveria toda a palavra em letra maiúscula, ignorando completamente a acentuação, por exemplo), podemos concluir que os tradutores lidam de forma engenhosa com a zona de equi valência real do texto e conseguem manter a mesma função do texto de origem.

Partamos para o segundo recorte.

\section{Cena 2}

'Why didn't you ever go to school, Joe, when you were as little as me?'

'Well, Pip,' said Joe, taking up the poker, and settling himself to his usual occupation when he was thoughtful, of slowly raking the fire between the lower bars: ' $I$ 'll tell you. My father, Pip, he were given to drink, and when he were overtook with drink, he hammered away at my mother, most onmerciful. It were a'most the only hammering he did, indeed, 'xcepting at myself. And he hammered at me with a wigour only to be equalled by the wigour with which he didn't hammer at his anwil. - You're a-listening and understanding, Pip?'

'Yes, Joe.'

"Consequence, my mother and me we ran away from my father, several times; and then my mother she'd go out to work, and she'd say, 'Joe,' she'd say, 'now, please God, you shall have some schooling, child,' and she'd put me to school. But my father were that good in his hart that he couldn't abear to be without us. So, he'd come with a most tremenjous crowd and make such a row at the doors of the houses where we was, that they used to be obligated to have no more to do with us and to give us up to him. And then he took us home and hammered us. Which, you see, Pip,' said Joe, pausing in his meditative raking of the fire, and looking at me, 'were a drawback on my learning.'

'Certainly, poor Joe!'

(DICKENS 2013: 564)

\begin{tabular}{|c|}
\hline Tradução de Paulo H. Britto \\
"E por que nunca foste à escola, \\
Joe, quando eras pequeno como eu?"
\end{tabular}

"Bom, Pip", disse Joe, pegando o atiçador e assumindo sua ocu pação habitual sempre que estava pensativo, de lentamente atiçar o fogo por entre as grades mais baixas, "vou te contar. Meu pai, Pip, era chegado à bebida, e quando ficava chumbado ele martelava a minha mãe sem dó. Era quase que só nessas vez que ele martelava alguma, quer dizer, e também quando martelava eu. E ele me martelava com toda a força que ele não punha quando martelava a bigorna dele. - Estás es cutando e compreendendo, Pip?”

Tradução de Doris Goettems
“Por que você nunca foi à escola,
Joe, quando tinha o meu tamanho?"
“Bem, Pip”, disse Joe, pegando o
atiçador e se dedicando à sua ocupação
habitual, quando estava pensativ o, de
avivar o fogo lentamente, entre as barras
mais baixas da lareira: “eu vou lhe
contar. Meu pai, Pip, era dado a beber, e
quando ele bebia demais, ele batia com
o martelo na minha mãe, sem a menor
piedade. Ela era a única pessoa em quem
ele batia, na verdade, exceto eu. E ele
me batia com toda forç a, com um vigor
que ele não tinha para bater na sua
bigorna. Você está escutando, Pip? Está
entendendo?

ando tinha o meu tamanho?"

atiçador e se dedicando à sua ocupação habitual, quando estava pensativ 0 , de avivar o fogo lentamente, entre as barras mais baixas da lareira: "eu vou the contar. Meu pai, Pip, era dado a beber, e quando ele bebia demais, ele batia com o martelo na minha mãe, sem a menor piedade. Ela era a única pessoa em quem ele batia, na verdade, exceto eu. E ele me batia com toda forç a, com um vigor bigorna. Você está escutando, Pip? Está entendendo? 


\begin{tabular}{|c|c|}
\hline $\begin{array}{l}\text { “Estou, Joe.” } \\
\text { “E em consequência eu e a minha } \\
\text { mãe fugiu do meu pai, mais de uma vez; } \\
\text { e aí minha mãe ia trabalhar e ela me } \\
\text { dizia: 'Joe', dizia ela, 'agora se Deus } \\
\text { quiser, vais estudar um pouco', e aí ela } \\
\text { me punha na escola. Mas o meu pai tinha } \\
\text { bom coração e não conseguia viver sem } \\
\text { nós. E aí ele vinha com um monte de } \\
\text { gente e fazia uma barulheira tamanha na } \\
\text { porta da casa onde n ós estava, que aí } \\
\text { eles não tinha jeito de não entregar nós } \\
\text { pra ele. E aí ele levava nós pra c asa e } \\
\text { martelava nós. E isso, Pip, tu entendes”, } \\
\text { disse Joe, fazendo uma pausa no s eu } \\
\text { pensativo atiçar do fogo, e olhando para } \\
\text { mim, "prejudicou um bocado os meus } \\
\text { estudo." } \\
\text { “É claro, Joe, pobre de ti!” }\end{array}$ & $\begin{array}{l}\text { “Sim, Joe." } \\
\text { “Por causa disso, minha mãe e eu } \\
\text { corremos para longe do meu pai muitas } \\
\text { vezes, e então a minha mãe tinha que } \\
\text { sair para trabalhar, e ela dizia, 'Joe, se } \\
\text { Deus permitir, você vai ter alguma } \\
\text { instrução, meu filho' e ela me botou na } \\
\text { escola. Mas meu pai tinha isso de bom } \\
\text { nele, não podia ficar bnge de nós. Assim, } \\
\text { ele veio com um monte de gente e éz tal } \\
\text { rebuliço nas portas das casas onde nós } \\
\text { estávamos, que eles foram obrigados a } \\
\text { nos despachar de uma vez por todas, e } \\
\text { nos entregar para ele. E então ele nos } \\
\text { levou para casa e nos bateu de novo. E } \\
\text { isso, como você vê, Pip” disse Joe, } \\
\text { parando de avivar o fogo e olhando para } \\
\text { mim, “não ajudou e m nada a minha } \\
\text { educação." } \\
\text { "Certamente que não, p obre } \\
\text { Joe!" } \\
\text { (pp. 56) }\end{array}$ \\
\hline
\end{tabular}

Enquanto na cena 1, observamos uma zona de equivalência real gerada por limites relativos às questões linguísticas, mais especificamente, quanto à variação intralinguística estabelecida pelo uso motivado dos signos pelo autor, nesta cena 2, temos outros aspectos a considerar.

Um primeiro aspecto que não é contemplado especificamente no trecho citado, mas que per meia todo o texto meta é a questão do c omportamento tradutor em relação à norma inicial adotada. Podemos citar a escolha quanto a traduzir ou não os nomes próprios. Em ambas as traduções analisadas, os tradutores optaram por traduzir alguns nomes próprios, como o do bar local "Blue Boar" no original e traduzido igualmente nas duas obras por "Javali Azul", e por não traduzir os nomes dos personagens (Herbert, Phillip, etc.) nem dos bairros de Londres (Hammersmith, Richmond, etc.), por exemplo. Como se vê, coube ao tradutor definir qual o material que se poderia traduzir, mas que não se traduz, como esclarece Radabán (1991: 131).

Entretanto, a zona de inequivalência que nos parece a mais significativa no trecho selecionado, diz respeito à variação intralinguística que se estabelece 
HeNGE, G. da S. - Discutindo a (in)equivalência: um exercício de análise

entre o registro padrão util izado pelo narrador-personagem e outros personagens do enredo e o registro util izado pelo personagem Joe Gargery, o ferreiro casado com a irmã de Pip.

Na cena 2, podemos identificar de forma bastante clara esta dis tinção. Como tal, é uma escolha do autor apresentar variação linguística parcial como modo de caracterização da personagem. Joe é um ferreiro humilde do interior, sem instrução formal e que trabalha di a após dia na ferraria anexa à própri a casa. Seu modo de falar pertence, por tanto, a uma classe econômi ca desprivilegiada que contrasta gritantemente com os ricos e poderosos com que Pip conviverá no decorrer da trama, sentindo-se, inclusive envergonhado pelo modo como Joe se expressa verbalmente (em outra passagem da história). Em síntese, podemos dizer que existe variação de registro linguís tico no texto de origem com a função de caracterizar, pela linguagem, as classes sociais distintas a que pertencem os personagens. Tal função, portanto, é importante e constitui um elemento relevante do texto literário.

Os tradutores precisam, então, lidar com essa variação de registro em seus textos meta. No caso das traduções de Britto e Goettems, cada um geriu de forma distinta esta variação como podemos ver na cena 2 des tacada. Enquanto Britto tenta recriar o registro de fala de Joe através do uso de um registro equivalente à diferença entr e classes no português brasileiro, Goettems prefere apagar esta distinção presente no texto de origem.

Observemos, por exemplo, a variação selecionada por Britto: em “er a quase que só nessas vez que ele martel ava alguma” e "prejudicou um bocado os meus estudo" a concordância de número não segue a norm a dita culta do português. Há ainda o excessivo uso da conjunção "que”, além do uso de "aí" como principal conector entre as orações e também o uso do pronome pessoal reto em lugar do oblíquo como em "[ele] martelava eu” ou "não tinha jeito de não entregar nós pra ele".

Já a tradução de Goettems si mplesmente homogeneíza os $r$ egistros existentes no texto e Joe passa a usar a mesma variação linguística dos demais personagens, como podemos ver em "ela era a única pessoa emquem ele batia” ainda "minha mãe e eu corremos para longe". 
Neste caso do registro social do ferreiro no romance, estabelece-se uma zona de inequivalência real, pois as classes sociais são historicamente distintas ainda que com traços de similaridade em cada país. Tal inequivalência ainda diz respeito a uma natural diac ronia quando o tradutor seleciona um regi stro no português brasileiro do final do sécul o XX, início do XXI, pois o registro no texto de origem data de um registro do inglês britânico da metade do século XIX.

Porém, cabe ainda observar outro limite, de caráter ontológico, segundo Radabán (1991), na tradução de Britto. Em seu texto meta, Britto estabele ce várias marcações (mais gramaticais do que lexicais) do registro popular usado pelo ferreiro. Entretanto, o mesmo personagem utiliza a conjugação verbal em $2^{a}$ pessoa do sin gular de forma padrão, como vemos em "estás escutando e compreendendo, Pip?" ou ainda “vais es tudar um pouco”. Tal ocorrência não se dá, us ualmente, com as mesmas ocorrências de não marcação da concordância nominal como vimos acim a ou do uso pronomi nal oblíquo nos registros sociais de classes economicamente desfavorecidas. O que leva-nos a acreditar que se trata de uma lacuna do conhecimento do registro selecionado pelo tradutor.

Ainda discutindo as limitações de caráter ontológico para a equivalência, podemos observar a escolha do tempo ve rbal no trecho em que Joe relembr a sua infância por parte de cada um dos tradutores. No registro linguístic o do ferreiro, no texto original, temos "my mother she'd go out to work, and she'd say" e "she'd put me to school" e ainda "So, he'd come with". Há, portanto, uma conjugação não padrão dos verbos. Cada um dos dois tradut ores lidou de forma diferente com esta ocorrência. Br itto propôs a função do verbo como marcação do pretérito imperfei to do indicativo, provavelmente influenciado pelo "several times" na frase inicial de Joe. Ou seja , o tradut or optou por retratar as fugas da mãe com o pequ eno Joe como corriqueiras, ocorrendo várias vezes, mas sempre com o mesmo døfecho (o retorno ao lar e o recomeço das agressões), assim, temos "aí ela ia trabahar" e "aí ela me punha na escob" ou “aí ele levava nós para casa e martelava nós”. Já Goettems opta pelo verbo no pretérito perfeito, o que leva a outra função do elemento narrado, a 
Henge, G. da S. - Discutindo a (in)equivalência: um exercício de análise

descrição de uma ú nica ocorrência do fato, isto é, como se o pai os tiv esse agredido poucas vezes. Isto fica eviden te em "e ela me botou na escola" ou ainda "ele veio com um monte de gente" e "ele nos levou para csa e nos bateu de novo".

Para encerrar esta análise, destacamos outra zona de inequivalência real estabelecida por questões linguísticas na cena 2: a ambi guidade. Como podemos ver, o autor utiliza o verbo "hammer" para expressar como o pai os tratava: "he hammered away at my mother" e "It were a'most the only hammering he did" ou ainda, "he hammered at me". Tal escolha verbal remete ao verbo martelar, já que hammer significa a ferramenta utilizada para quebrar ou fixar coisas. Sendo o pai de Jœe um ferreiro, seu ofício implicava no uso do martelo como ferramenta de trabalho para moldar e tornear o ferro.

0 autor do romance, portanto, estabelece uma ambiguidade entre o uso do martelo como meio de subsis tência ou como forma de ag ressão física, de manifestação de violência domés tica. Não há evidênci as linguísticas no tex to para cogitar que a agressão possa ter sido ser realizada específic a ou exclusivamente com esta ferramenta, ou seja, a ambigui dade marcada pela ocorrência do termo em do is contextos distintos permanece válida e per mite que se pense "martelar alguém" como um uso figurativo do termo para agressão física. Logo, a ambiguidade intenciona l é uma área de inequi valência real, (RABADÁN 1991: 123) e deve ser tratada como tal pelo tradutor.

Os dois tradutores aqui analisados lidaram de forma distinta com tal ambiguidade. Enquanto Britto a mantev e no text o meta opta ndo por us ar o verbo "martelar" como um equivalente, como se nota em "ele martelava a minha mãe" e "quando martelava a bigorna dele", Goettems estabeleceu como equivalente o verbo "bater" e apagou a ambiguidade delimitando a forma de agressão do pai em "ele batia com o martelo na minha mãe" ou ainda "ele me batia com toda a força".

Após este exercício de análise, pudem os identificar algumas questões apontadas pelos teóricos como de extrema relevância para o fazer tradutóri o, uma vez que ca da texto constitui uma reformulação, a partir dos meios da língua para qual se traduz, como de fine Hurtado Albir (2001). Assim, ainda 
apresentando plena fidelidade com o texto de origem, cada tradutor encontrou soluções distintas para as zonas de inequivalência presentes.

\section{Considerações finais}

Neste artigo bus quei discutir a noçã o de inequivalência em tradução. Para tanto, procurei fazer uma revisã o breve, porém relevante da noçã o de equivalência e das possibilida des de inequivalência que se estabelecem no processo tradutório.

Ao longo dos Estudos da Tradução, muitos teóricos buscaram e ainda buscam definir o que é equivalência, daí por que nã o partimos de uma no ção dada e encerrada. Então, selecionamos aqui uma perspectiva, tomando como principais autores Hurtado Albir, Pym e Rabadán e nos propusemos a anal isar um texto literário buscando i dentificar as possíveis (in)equivalências nele existentes.

Através da análise das duas cenas do $r$ omance "Great Expectations" (1861) de Charles Di ckens e de suas tr aduções para o português brasileiro, verificamos que, de fato, as inequivalências podem ser estabelecidas a partir de questões muito variadas, tanto intra quanto extralinguísticas e que o papel do tradutor é crucial em seu encaminhamento delas. Mais do que isto, podemos perceber o quanto a fundamentação teórica é importante para que o tradutor perceba as zonas de inequivalência real no texto a traduzir e busque soluções adequadas e/ou viáveis.

\section{Referências bibliográficas}

AUBERT, F. As (in)fidelidades da tradução. Campinas, SP: UNICAMP, 1993. BASSNETT, S. Translation Studies. Third edition. New York: Routledge, 2002. 
DiCKENS, C. Grandes Esperanças. Edição Bilíngue. Tradutor Dóris Goettems. São Paulo: Landmark, 2013. . Grandes Esperanças. Tradutor Paulo Henriques Britto. São Paulo: Penguin Companhia das Letras, 2012. . Great Expectations. Edição Bilíngue. São Paulo: Landmark, 2013. HURTADo ALBIR, A. Tradución y Traductologia. Introducción a la Traductologia. Madrid: Ediciones Cátedra, 2001.

PYM, A. Teorías contemporáneas de la traducción. Tarragona: Intercultural Studies Group, 2011.

RABADÁN, R. Equivalencia y Traducción. Léon: Univ ersidad, Secretariado de Publicaciones, 1991.

WoTJAK, G. Equivalencia semântica, equivalencia comunicativa y equivalencia translémica. Hieronymus Complutensis. n. 1. Centro Virtual Cervantes, s.d. 